\title{
Suppression of matrix metalloproteinase production by hCG in cultures of human luteinized granulosa cells as a model for gonadotrophin-induced luteal rescue
}

\author{
A. Stamouli, M. J. B. O'Sullivan, S. Frankel, E. J. Thomas and \\ M. C. Richardson \\ Obstetrics and Gynaecology, University of Southampton, Princess Anne Hospital, Coxford Road, \\ Southampton SO16 5 YA, UK
}

\begin{abstract}
Granulosa cells were isolated from follicular aspirates collected at ovum recovery for in vitro fertilization. Cells were cultured in a defined medium on artificial extracellular matrix (Matrigel) in the presence or absence of hCG as a model for corpus luteum function. Release of cells from this culture system is reduced by hCG and this effect may be mediated through an inhibition of extracellular matrix degradation. Using zymography and western blot analysis, we confirm the identity of matrix metalloproteinases-2 and -9 in culture media. Matrix metalloproteinase- 9 was the predominant gelatinase in freshly prepared granulosa cells and in culture media, and also represented a major metalloproteinase component in homogenates of early and mid-luteal phase samples of corpora lutea. Quantitative analysis of matrix metalloproteinases in culture media, obtained throughout the 14 day culture period and expressed per $\mu \mathrm{g}$ of DNA, showed that matrix metalloproteinase-2, undetectable on day 2 , rose throughout the culture period and that this rise was significantly inhibited by hCG. In contrast, matrix metalloproteinase- 9 was clearly detectable on day 2 and remained relatively constant throughout much of the culture (day 2 to day 12) in the presence of gonadotrophin. Significantly increased production of matrix metalloproteinase-9 (day 6 to day 12) was evident in the absence of hCG. Our results provide further evidence for the hypothesis that the rescue of the corpus luteum in early pregnancy involves the maintenance of cellular function through the stabilization of the extracellular matrix.
\end{abstract}

\section{Introduction}

The formation and regression of the corpus luteum involve intense cellular differentiation and tissue remodelling. Regulated changes in extracellular matrix (ECM) may be important in these events (reviewed by Luck, 1994). During early pregnancy in women, embryo-derived hCG rescues the corpus luteum and prolongs progesterone production, whereas in a nonconception cycle the corpus luteum regresses. It has been proposed that, in the rat corpus luteum, regression may be associated with ECM instability resulting from the action of matrix metalloproteinases (MMPs; Endo et al., 1993). This would be consistent with the idea proposed by Aston et al. (1996a) that luteal rescue in women may involve maintenance of ECM stability through the suppression of MMP action by hCG. Matrix metalloproteinases are zinc proteases with a range of specificities directed towards various components of the extracellular matrix (Birkedal-Hansen et al., 1993). They are inhibited by tissue inhibitors of metalloproteinase (TIMP) $-1,-2$ and -3 , which bind to metalloproteinases noncovalently blocking their action (Nagase, 1994). The MMPs present in rat

Received 9 January 1996. corpora lutea (Endo et al., 1993) and 4-day-old bovine corpora lutea (Tsang et al., 1995) appear to be MMP-2 and MMP-9, with MMP-2 as the predominant form. Studies on human luteinized granulosa cells (Puistola $e t$ al., 1995; Aston et al., 1996a) have also demonstrated the presence of MMP-2 and MMP-9, although there is disagreement as to which MMP predominates. The discrepancy between these studies may derive from the use of different culture conditions. Whether MMP production can be influenced by gonadotrophins remains an open question. Tsang et al. (1995) have shown that MMP production was not regulated by LH in cows. However, in cultures of luteinized human granulosa cells, Aston et al. (1996a) showed that overall gelatinase activity per cell was suppressed by $\mathrm{hCG}$, an effect that may have been partially mediated by higher concentrations of TIMP in gonadotrophinstimulated cultures. The possibility that hCG may suppress MMP activity in the human corpus luteum in vivo has also been suggested in a preliminary report by Duncan et al. (1995).

The present study extends earlier work (Aston et al., 1996a) by positively identifying MMP- 2 and MMP-9 in culture media of human granulosa cells by western blotting. The predominance of MMP-9 in fresh and cultured cells is confirmed and shown to be consistent with analysis of MMPs present in 
samples of human corpora lutea. Using a culture system that appears to show aspects of luteal rescue in vitro, possibly through stabilization of ECM (Aston et al., 1996a), we show that hCG appears to downregulate the production of MMP-9 and MMP-2. This work provides further evidence that rescue of the corpus luteum of early pregnancy involves hCG-induced suppression of ECM degradation.

\section{Materials and Methods}

\section{Patients}

Tissue was collected according to protocols approved by our local Ethical Committee and with the informed consent of the patients. Follicular aspirates and washes were obtained at ovum collection for in vitro fertilization. The patient protocol (described by Jenkins et al., 1991) involved pituitary downregulation with gonadotrophin releasing hormone analogue (buserelin; $200 \mu \mathrm{g}$ intranasally three times a day), followed by ovarian stimulation with human menopausal gonadotrophin (4 ampoules per day) and follicular maturation with hCG (10 $000 \mathrm{iu}$ ). Follicles aspirated were $>15 \mathrm{~mm}$ in diameter and the concentration of circulating oestradiol was consistent with the number and sizes of follicles present.

Samples of corpora lutea were obtained from ovaries previously removed at hysterectomy performed for reasons unconnected with the study. Patients were not on medication. An approximate dating of luteal age was obtained from menstrual history.

\section{Cell preparation and culture}

Granulosa cells were prepared from combined follicular aspirates and washes according to the method described by Richardson et al. (1992). Each experiment refers to work carried out with cells from an individual patient. The medium used for preparation and culture was a mixture (50:50) of Ham's F12 and Dulbecco's modified Eagle's medium (Imperial Laboratories, Andover) supplemented with glutamine $\left(2 \mathrm{mmol}^{-1}\right)$, penicillin (50 $\left.\mathrm{mg} \mathrm{l}^{-1}\right)$, streptomycin $\left(60 \mathrm{mg} \mathrm{I}^{-1}\right)$, amphotericin $\left(2.5 \mathrm{mg} \mathrm{l}^{-1}\right)$ and ITS-plus (providing insulin $6.25 \mathrm{mg} \mathrm{I}^{-1}$, transferrin $6.25 \mathrm{mg} \mathrm{l}^{-1}$, selenious acid $6.25 \mu \mathrm{g} \mathrm{l}^{-1}, \mathrm{BSA}^{\prime}$ $1.25 \mathrm{~g} \mathrm{I}^{-1}$ and linoleic acid $5.35 \mathrm{mg} \mathrm{l}^{-1}$; Universal Biologicals, London). Twenty-four-well culture plates were coated with a thin layer of Matrigel (Stratech, Luton) which provides a model for basement membrane. The Matrigel preparation was diluted I:I with medium; $50 \mu \mathrm{l}$ was dispensed and spread over the surface of each well; the plate was tilted and the excess removed. The cells were plated out at approximately $2-5 \times 10^{5}$ cells $\mathrm{ml}^{-1}$ (incubate volume $\mathrm{Iml}$ ) and cultured at $37^{\circ} \mathrm{C}$ in $5 \%$ $\mathrm{CO}_{2}$ in air. The amount of hCG used in culture was chosen to be just maximal for progesterone production (Richardson et al., 1992). The medium was changed every $48 \mathrm{~h}$ and the cells were cultured for a total of 14 days. At each medium change, adherent cells were assessed by DNA assay. Duplicate wells for each treatment were scraped into assay buffer, sonicated and assayed for DNA content by the method described by Labarca and Paigen (1980) using calf thymus DNA as standard.

\section{Corpus luteum homogenization}

Samples of corpora lutea were placed in PBS and stored in liquid nitrogen. The tissue was thawed and homogenized using an Ultra-turrax T8 homogenizer (BDH, Poole) in homogenization buffer (approximately $10 \mathrm{mg}$ tissue $\mathrm{ml}^{-1}: 0.25 \mathrm{~mol} \mathrm{l}^{-1}$ sucrose, $25 \mathrm{mmol} \mathrm{l}^{-1}$ Tris- $\mathrm{HCl}, \mathrm{pH} 7.4$ ). The protein content of the samples was assayed using a protein assay kit (Bio-Rad, Hemel Hempstead) based on the method described by Bradford (1976).

\section{Zymography}

Granulosa cell cultured conditioned medium collected every $48 \mathrm{~h}$ was assessed by zymography for gelatinase activity. SDS-PAGE was used with the addition of $0.8 \mathrm{mg}$ gelatin $\mathrm{ml}^{-1}$ (Herron et al., 1986) to a $7.5 \%$ resolving gel. Samples of culture media ( $15 \mu \mathrm{l})$ were electrophoresed directly, while homogenates of corpora lutea and freshly prepared granulosa cells were diluted in homogenization buffer $\left(0.25 \mathrm{~mol}\right.$ sucrose $1^{-1}$, $25 \mathrm{mmol}$ Tris- $\mathrm{HCl}^{-1}, \mathrm{pH} 7.4$ ) to a final concentration of $10 \mu \mathrm{g}$ protein per $15 \mu \mathrm{l}$ per lane. Positive controls included pure MMP-2 (Biogenesis, Poole) and MMP-9 (kindly donated by G. Murphy, Strangeways Laboratory, Cambridge). The samples were electrophoresed at $40 \mathrm{mV}$ for the first $10 \mathrm{~min}$ and then at $80 \mathrm{mV}$ for a further $90 \mathrm{~min}$ in buffer $\left(25 \mathrm{mmol}\right.$ Tris $\mathrm{l}^{-1}$, $0.4 \mathrm{~mol}$ glycine $\mathrm{I}^{-1}$ and $1 \%(\mathrm{w} / \mathrm{v})$ SDS). Subsequently, the gels were washed in $2.5 \%(\mathrm{v} / \mathrm{v})$ Triton-X100 for $30 \mathrm{~min}$ and incubated overnight in buffer $\left(50 \mathrm{mmol}\right.$ Tris- $\mathrm{HCl} \mathrm{l}^{-1}$, $5 \mathrm{mmol} \mathrm{CaCl} \mathrm{l}^{-1}, \mathrm{pH} \mathrm{8.0)}$. Addition of zinc chelators such as $5 \mathrm{mmol} \mathrm{EDTA}^{-1}$ or $2 \mathrm{mmol} 1,10$ phenanthroline $\mathrm{l}^{-1}$ to the incubation buffer abolished gelatinase activity; this served as a negative control. Gelatinase activity was visualized as clear bands against a blue background, after staining in Coomassie blue and destaining in 30\% methanol:10\% acetic acid in water.

\section{Densitometric analysis}

Bands of gelatinase activity were analysed for intensity and surface area by scanning densitometry on a Sharp JX-330P transmissive scanner using the Intelligent Quantifier ${ }^{(x)}$ software package (Biolmage ${ }^{\mathrm{R}}$, Crewe). An intensity index was calculated for each band, expressed per $\mu \mathrm{g} D \mathrm{DA}$, converted into a percentage of day 14 control (for MMP-2) and day 2 control (for MMP-9) and plotted against days in culture (Fig. 4).

\section{Western blotting}

Before western blot analysis for MMP-2, media samples were purified as follows. Fifty millilitres post-day 2 control culture medium (that is, from cultures not treated with hCG) was dialysed against 20 mmol sodium phosphate $\mathrm{l}^{-1}(\mathrm{pH} 7.0)$ in the presence of $10 \mu \mathrm{l}$ sheep anti-human MMP-2 (kindly donated by G. Murphy). The dialysed material was then applied to a HiTrap Protein-G column (Pharmacia, St Albans) which removed all MMP-2 as assessed by zymography. MMP-2 was subsequently eluted with $1 \%(\mathrm{w} / \mathrm{v})$ SDS in buffer. The sample was then concentrated a further tenfold using an Ultrafree-MC filter unit (Sigma, Poole). Culture media analysed for MMP-9 were used directly. 


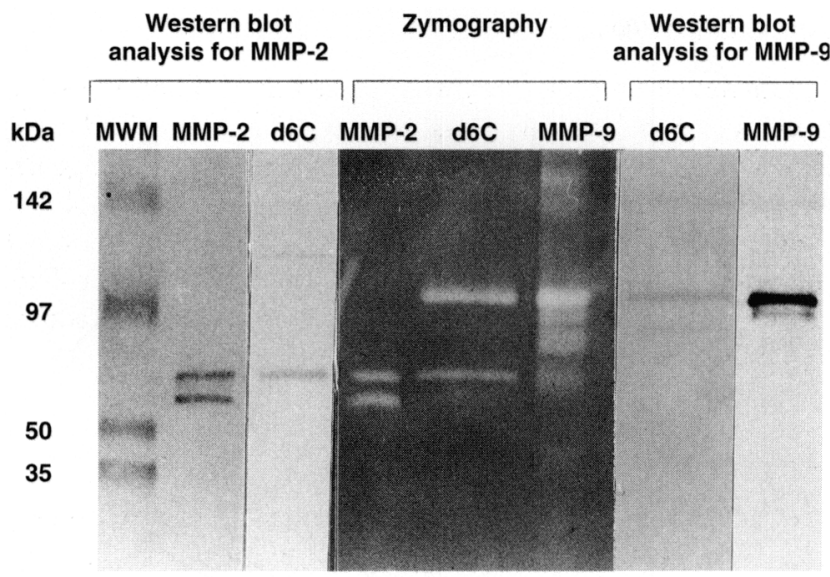

Fig. 1. Zymography of gelatinases present in culture medium from cultures of luteinized granulosa cells compared with reference preparations of MMP-2 and MMP-9 (central panel); MMP-2/MMP-9, reference preparations; d6C, medium from day 6 control cultures maintained without gonadotrophin. Western analysis for MMP-2 after purification from culture media (left-hand panel) and western analysis for MMP-9 (right-hand panel). MWM, positions of molecular markers markers $(142,97,50$ and $35 \mathrm{kDa})$.

The samples were electrophoresed on $7.5 \%$ SDSpolyacrylamide gels as described above but with the omission of gelatin. The proteins were then transferred on to nitrocellulose membranes at $100 \mathrm{mV}$ for $1 \mathrm{~h}$. The membranes were incubated in BSA ( $1 \mathrm{mg} \mathrm{ml}^{-1}$ ) for $1 \mathrm{~h}$ to prevent nonspecific binding before overnight incubation at $4^{\circ} \mathrm{C}$ with the primary antibody of interest (sheep anti-human MMP-2, kindly donated by G. Murphy, and mouse anti-human MMP-9, Oncogene Science, Cambridge). Subsequent incubations with alkaline phosphatase conjugated secondary antibodies and nitroblue tetrazolium (both from Sigma) revealed red/blue bands. All incubations and dilutions were performed in Tris-buffered saline $\left(50 \mathrm{mmol}\right.$ Tris $\left.1^{-1}, 150 \mathrm{mmol} \mathrm{NaCl} 1^{-1}, \mathrm{pH} 7.5\right)$ supplemented with $0.1 \%(\mathrm{v} / \mathrm{v})$ Tween 20 .

\section{Statistical analysis}

The data were subjected to nonparametric analysis of variance of repeated measures using day of culture and \pm hCG as variables. ANOVA demonstrated significant effects of hCG throughout the culture period. Significance was calculated using the Wilcoxon test for paired nonparametric data.

\section{Results}

Two gelatinases were apparent in granulosa cell-conditioned medium (day 6 control) with molecular masses consistent with MMP-9 (92 kDa) and MMP-2 (72 kDa) (Fig. 1). These two MMP species co-electrophoresed with their respective standards. After purification and concentration of the minority MMP-2 component, its identity was confirmed by western analysis using a specific anti-MMP-2 antibody. Similar methodology confirmed the identity of the predominant MMP-9 band without prior concentration.
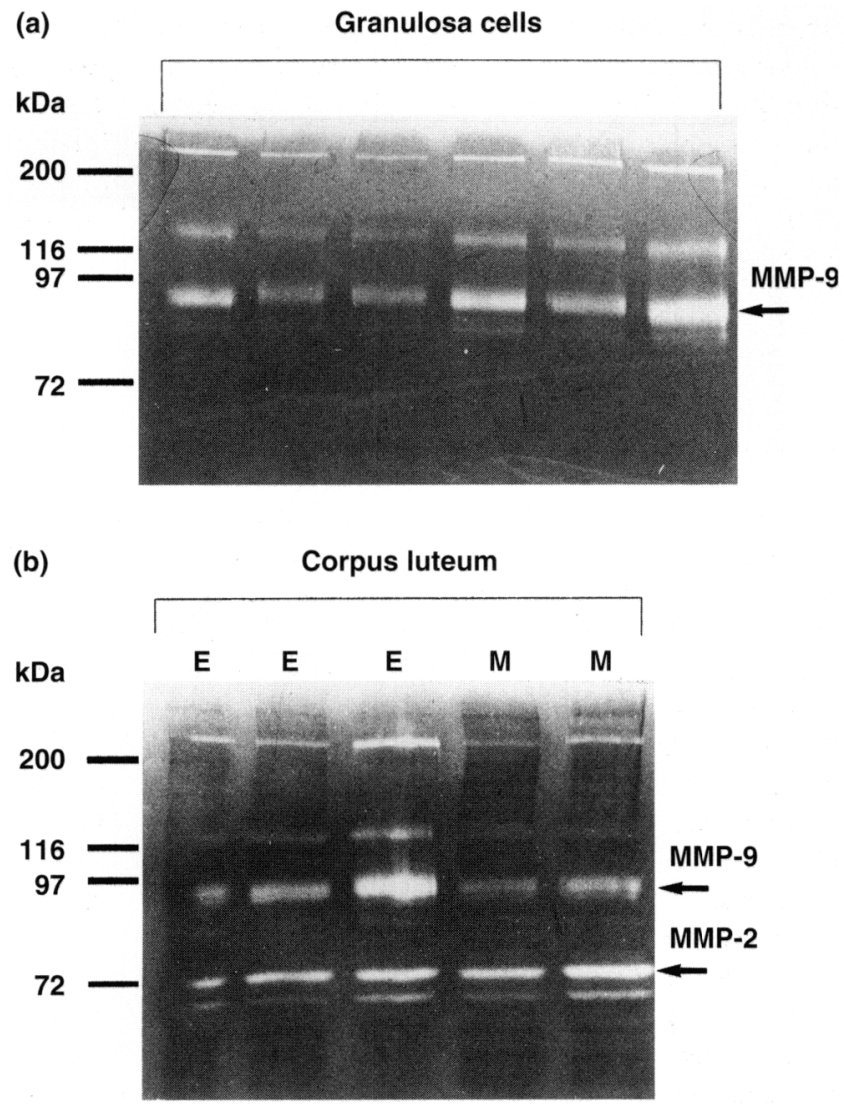

Fig. 2. Zymography of homogenates of (a) freshly prepared granulosa cells and (b) samples of corpora lutea designated as early (E) or mid-(M) luteal phase. All lanes were loaded with $10 \mu \mathrm{g}$ cellular protein. Positions of molecular markers are noted (left) as well as presumed identities of MMP-2 and MMP-9 (right).

The pattern of gelatinases present in homogenates of freshly prepared granulosa cells from five separate patients is shown (Fig. 2a). All preparations showed the predominant MMP-9 band (with some processing to the lower molecular mass $82 \mathrm{kDa}$ active species) and an absence of MMP-2. A higher molecular mass gelatinase (approximately $130-150 \mathrm{kDa}$ ) remained unidentified. Zymography of homogenates from samples of five separate corpora lutea (three early and two mid-luteal phase), loaded and run under identical conditions to those used for granulosa cells, again showed strong MMP-9 bands (particularly in early luteal samples), with narrower MMP-2 bands showing evidence of processing to the lower molecular mass $(67 \mathrm{kDa})$ activated form (Fig. 2b). A higher molecular mass form of gelatinase similar to that described for the granulosa cell homogenates above was also recognized but remained unidentified.

The relationships between MMP concentration and intensity index obtained after densitometric analysis of zymograms obtained after electrophoresis of standard, reference preparations of MMP-2 and MMP-9 are shown (Fig. 3). The two relationships (intensity index against - $\log [\mathrm{MMP}-2]$ and - $\log [$ MMP-9]) were sufficiently linear to allow the intensity index to be used as a quantitative measure of enzyme activity in samples of culture media. The greater activity of the reference MMP-2 preparation (in terms of intensity index 
(a)

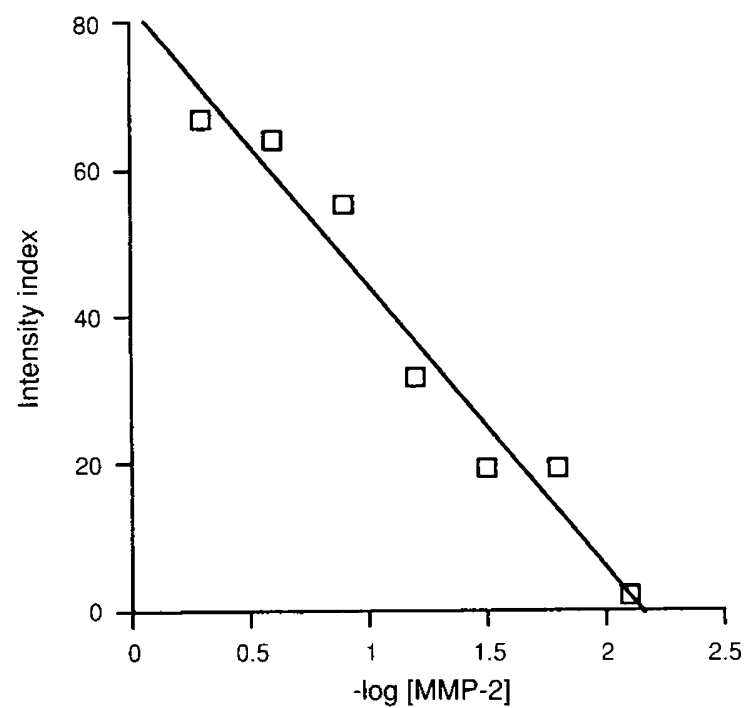

(b)

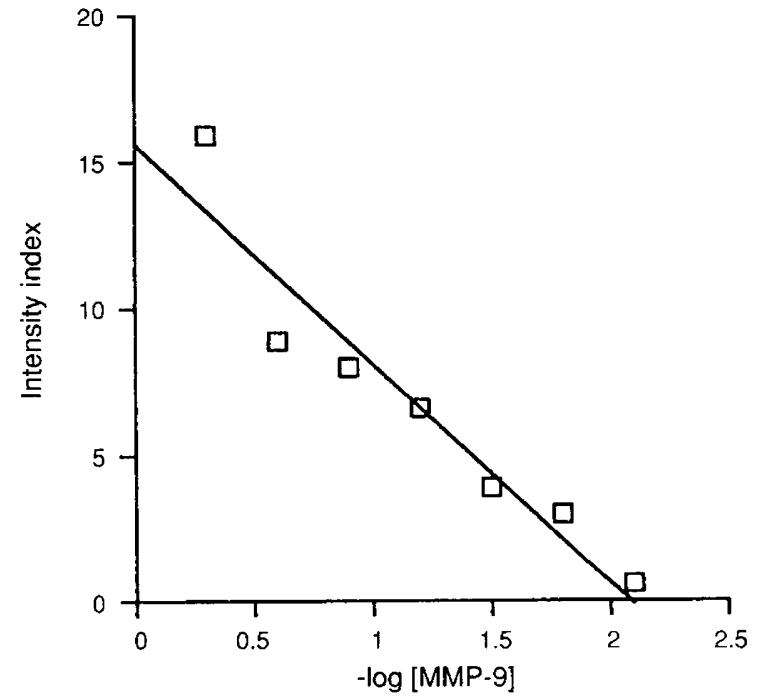

Fig. 3. Relationship of intensity index (as measured by image analysis of bands obtained on zymography) to concentration of (a) MMP-2 and (b) MMP-9, expressed as $\mu \mathrm{g} \mathrm{ml}^{-1}$ and converted to -log[MMP].

$\mu \mathrm{g}^{-1}$ protein) is only partially explained by its lower molecular mass compared with MMP-9.

Changes in the activity of MMP-2 and MMP-9, as measured by the intensity index of electrophoretic bands, were examined in culture media obtained throughout 14-day experiments in which cells were cultured with and without a maximal concentration of hCG (100 ng ml- ${ }^{-1}$ ). Combined data from six separate preparations are illustrated (Fig. 4). MMP-2 was not detectable at the beginning of the culture period (Fig. 4a). Becoming detectable by day 4, MMP-2 production then rose progressively throughout the culture period. This rise was suppressed by gonadotrophin so that by days 12-14, MMP-2 output was clearly and significantly lower in hCG-treated cells. It should be noted that MMP-2 remained a minority component of overall gelatinase activity throughout. Thus, by the end (a)

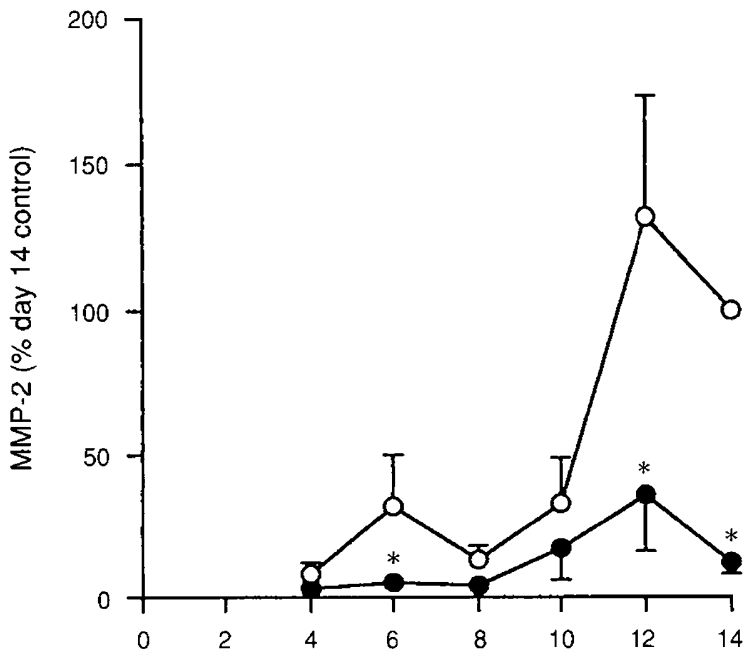

(b)

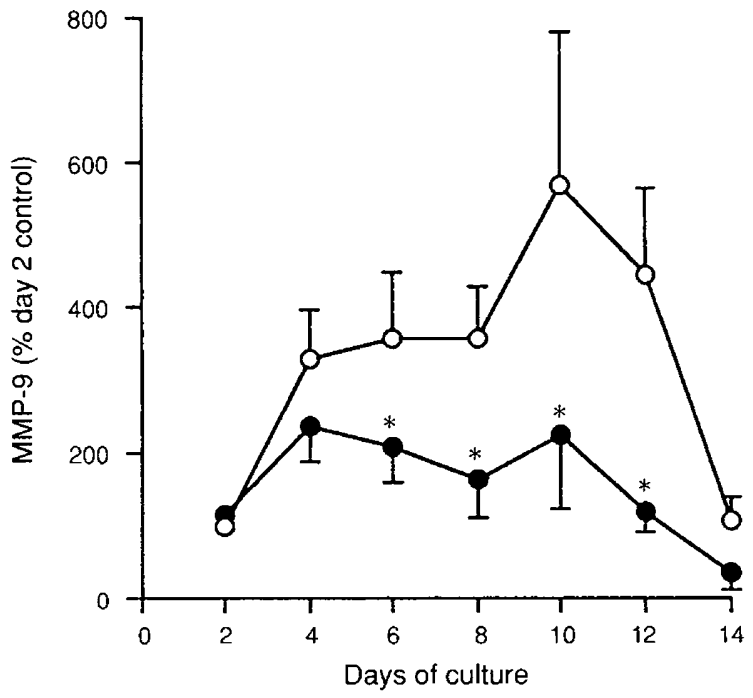

Fig. 4. Comparative amounts of (a) MMP-2 and (b) MMP-9 in culture media obtained from cultures of luteinized granulosa cells maintained in the presence $(O)$ or absence $(O)$ of hCG $\left(100 \mathrm{ng} \mathrm{ml}^{-1}\right)$. Values were calculated from the intensity index of electrophoretic bands corrected for $\mu \mathrm{g}$ cellular DNA estimated at each time point in the presence and absence of hCG. Results were expressed as percentage of control values on day 14 (for MMP-2) or day 2 (for MMP-9) and means were subsequently plotted from data derived from six separate preparations, with SEM. Absolute values in intensity index units per $\mu \mathrm{g}$ DNA were day 14 control MMP-2, $1015 \pm 698$, and day 2 control MMP-9, $1449 \pm 638 .{ }^{*} P<0.05$.

of the culture period, MMP-2 still represented only $20-30 \%$ of total gelatinase activity (MMP-2 plus MMP-9). Changes in MMP-9 production showed a different pattern (Fig. 4b). Substantial MMP-9 output was evident from the beginning of the culture, and this was maintained in the presence of hCG for much of the culture period (particularly days 4-12). In the absence of gonadotrophin, MMP-9 output was more variable and significantly increased (days 6-12). 


\section{Discussion}

The finding that the predominant form of MMP in luteinized granulosa-cell conditioned medium is MMP-9 confirms an earlier study (Aston et al., 1996a). Western blotting now provides positive identification of both the majority MMP-9 component and the minority MMP-2 enzyme, which needed purification and concentration before analysis. The observation that freshly prepared granulosa cells, when homogenized and subjected to zymography, showed no evidence of MMP-2 is consistent with the lack of this enzyme at the beginning of the culture period and confirms that the predominance of MMP-9 is not simply due to the specific culture conditions used. Our observations are further substantiated by strong bands of MMP-9 activity apparent on zymography of homogenates of corpus luteum, particularly those obtained in the early luteal phase.

The potential physiological importance of MMP-9 in corpus luteum function has not been previously recognized to our knowledge. Thus, although both MMP-2 and MMP-9 have been shown to be present in rat and bovine corpora lutea (Endo et al., 1993; Tsang et al., 1995), it is MMP-2 that predominates in both these species. Furthermore, a previous study on luteinized granulosa cells from women (Puistola et al., 1995), emphasized the presence of MMP-2 which appeared to accumulate preferentially after culture in serum-containing media. It is possible that the greater contribution of MMP-2 evident on zymography of corpus luteum as compared with granulosa cells, may be due to the presence of thecal cells.

Having established the identities of the gelatinases produced by luteinized granulosa cells in culture and how these related to those found in the corpus luteum, the main purpose of this study was to investigate regulation of MMPs by gonadotrophin. We have previously suggested that the culture system used, whereby human granulosa cells are maintained on ECM in serum-free medium, shows features that suggest that it may provide an in vitro model for corpus luteum function (Richardson et al., 1992). In the presence of hCG, progesterone production is well maintained for long periods in culture (up to 14 days; Aston et al., 1996b), and in the absence of gonadotrophin, cells eventually become detached from the culture surface, possibly through degradation of ECM (Aston et al., 1996a). We have speculated that this rescue of cellular function in vitro by hCG acts as a model for luteal rescue by hCG in vivo. The pattern of MMP production in this system does appear to mimic the changes occurring in human corpus luteum during the luteal phase (preliminary report by Duncan et al., 1995), particularly with regard to an increase in MMP-2 content towards the late luteal phase which can be suppressed by the administration of hCG in vivo. These in vivo studies also noted a predominance of MMP-9 in the early luteal phase and suppression of MMP- 9 by hCG (information presented but not detailed in abstract of Duncan et al., 1995).

The general principle that luteolysis may involve increased activity of gelatinases (particularly MMP-2 and MMP-9) is supported not only by work presented here, but also by the preliminary work of Duncan et al. (1995), and studies by Endo et al. (1993) on rat corpora lutea. The present study has concentrated on the production of MMPs irrespective of the presence of TIMP, which is removed during zymography.
Upregulation of TIMP by hCG in our model system (noted by Aston et al., 1996a) represents another level of complexity. Increased gelatinase activity in luteal regression may result from a combination of effects, including both differential production of MMPs (described in the present report) and falling TIMP expression. Rescue of luteal function by hCG in early pregnancy would involve both a suppression of MMP production and increased expression of TIMP. We suggest that enhanced stability of the ECM, induced by hCG, prevents luteal regression and enables an extension of cell survival into early pregnancy.

The authors thank the staff of the Wessex Fertility Unit, Princess Anne Hospital for the collection of follicular aspirates, G. Murphy, Strangeways Laboratory, Cambridge, for helpful advice and provision of purified metalloproteinases and antibodies, and M. I. P. Arthur, Department of Medicine, Southampton Medical School for his co-operation. The financial support of the MRC and the Solent Subfertility Trust is gratefully acknowledged.

\section{References}

Aston KE, Stamouli A, Thomas EJ, Vyas S, Iredale JP, Arthur MJP and Richardson MC (1996a) Effect of gonadotrophin on cell and matrix retention, and expression of metalloproteinases and their inhibitor in cultured human granulosa cells Molecular Human Reproduction 2 101-105

Aston KE, O'Sullivan MIB, Thomas EJ and Richardson MC (1996b) Effect of hCG on the detachment of human granulosa cells from extracellular matrix layered onto glass and plastic Human Reproduction $11336-340$

Birkedal-Hansen H, Moore WGI, Bodden MK, Windsor LJ, Birkedal-Hansen B, DeCarlo A and Engler JA (1993) Matrix metalloproteinases: a review Clinical Reviews in Oral Biology 4 197-250

Bradford MM (1976) A rapid and sensitive method for the quantification of microgram quantities of protein utilising the principle of protein dye binding Analytical Biochemistry $72 \quad 248-254$

Duncan WC, McNeilly AS and Illingworth PJ (1995) The effect of luteal rescue on the expression of matrix metalloproteinases and their inhibitors in the human corpus luteum Biology of Reproduction 52 Supplement 1112

Endo T, Aten RF, Wang F and Behrman HR (1993) Coordinate induction and activation of metalloproteinase and ascorbate depletion in structural luteolysis Endocrinology 133 690-698

Herron GS, Banda MJ, Clark EJ, Gavrilovic J and Werb Z (1986) Secretion of metalloproteinases by stimulated capillary endothelial cells. II Expression of collagenase and stromelysin activities is regulated by endogenous inhibitors Journal of Biological Chemistry 261 2814-2818

Jenkins JM, Davies DW, Devonport H, Anthony FW, Gadd SC, Watson RH and Masson GM (1991) Comparison of 'poor' responders with 'good' responders using a standard buserelin/human menopausal gonadotrophin regime for in vitro fertilization Human Reproduction 6 918-921

Labarca $C$ and Paigen K (1980) A simple, rapid and sensitive DNA assay procedure Analytical Biochemistry 102 344-352

Luck MR (1994) The gonadal extra-cellular matrix Oxford Reviews of Reproductive Biology 16 33-85

Nagase H (1994) Matrix metalloproteinases: a mini review. In Metalloproteinases and TIMP pp 85-93 Eds H Koide and T Hayase. Karger, Basel

Puistola U, Westerlund A, Kauppila A and Turpeenniemi-Hujanen T (1995) Regulation of $72-\mathrm{kDa}$ type IV collagenase-matrix metalloproteinase- 2 by oestradiol and gonadotropin-releasing hormone agonist in human granulosalutein cells Fertility and Sterility 64 81-87

Richardson MC, Davies DW, Watson RH, Dunsford ML, Inman CB and Masson GM (1992) Cultured human granulosa cells as a model for corpus luteum function: relative roles of gonadotrophin and low density lipoprotein studied under defined culture conditions Human Reproduction 7 12-18

Tsang PCW, Poff JP, Boulton EP and Condon WA (1995) Four-day-old bovine corpus luteum: progesterone production and identification of matrix metalloproteinase activity in vitro Biology of Reproduction 53 1160-1168 